\title{
1H-13C HSQC NMR spectroscopy for estimating procyanidin/prodelphinidin and cis/trans-flavan-3-ol ratios of condensed tannin samples: correlation with thiolysis
}

Article

Accepted Version

Zeller, W.E., Ramsay, A., Ropiak, H. M., Fryganas, C., MuellerHarvey, I., Brown, R. H., Drake, C. and Grabber, J. H. (2015) 1H-13C HSQC NMR spectroscopy for estimating procyanidin/prodelphinidin and cis/trans-flavan-3-ol ratios of condensed tannin samples: correlation with thiolysis. Journal of Agricultural and Food Chemistry, 63 (7). pp. 1967-1973. ISSN 0021-8561 doi: https://doi.org/10.1021/jf504743b Available at https://centaur.reading.ac.uk/39129/

It is advisable to refer to the publisher's version if you intend to cite from the work. See Guidance on citing.

To link to this article DOI: http://dx.doi.org/10.1021/jf504743b

Publisher: American Chemical Society

All outputs in CentAUR are protected by Intellectual Property Rights law, including copyright law. Copyright and IPR is retained by the creators or other copyright holders. Terms and conditions for use of this material are defined in the End User Agreement. 


\section{www.reading.ac.uk/centaur}

\section{CentAUR}

Central Archive at the University of Reading

Reading's research outputs online 


\section{${ }^{1} \mathrm{H}^{13} \mathrm{C}$ HSQC NMR Spectroscopy for Estimating Procyanidin/Prodelphinidin and Cis/Trans-Flavan-3-ol Ratios of Condensed Tannin Samples: Correlation with Thiolysis}

Wayne E. Zeller ${ }^{\dagger *}$, Aina Ramsay ${ }^{\ddagger}$, Honorata M. Ropiak, ${ }^{\ddagger}$ Christos Fryganas ${ }^{\ddagger}$, Irene Mueller-Harvey ${ }^{\ddagger}$,

Ronald H. Brown, ${ }^{\ddagger}$ Chris Drake, ${ }^{\ddagger}$ and John H. Grabber ${ }^{\dagger}$

'U.S. Dairy Forage Research Center, Agricultural Research Service, U.S. Department of Agriculture, 1925 Linden Drive West, Madison, Wisconsin 53706, United States

${ }^{\ddagger}$ Chemistry and Biochemistry Laboratory, Food Production and Quality Division, School of Agriculture, Policy and Development, University of Reading, P.O. Box 236, 1 Earley Gate, Reading RG6 6AT, United Kingdom 
1 ABSTRACT: Studies with a diverse array of 22 purified condensed tannin (CT) samples from

2 nine plant species demonstrated that procyanidin/prodelphinidin (PC/PD) and cis/trans-flavan-3-

3 ol ratios can be appraised by ${ }^{1} \mathrm{H}^{13} \mathrm{C}$ HSQC NMR spectroscopy. The method was developed from

4 samples containing 44 to $100 \%$ CT, PC/PD ratios ranging from 0/100 to 99/1, and cis/trans

5 ratios from 58/42 to $95 / 5$ as determined by thiolysis with benzyl mercaptan. Integration of cross-

6 peak contours of H/C-6' signals from $\mathrm{PC}$ and of $\mathrm{H} / \mathrm{C}-2^{\prime}, 6^{\prime}$ signals from $\mathrm{PD}$ yielded nuclei

7 adjusted estimates that were highly correlated with $\mathrm{PC} / \mathrm{PD}$ ratios obtained by thiolysis $\left(\mathrm{R}^{2}=\right.$

8 0.99). Cis/trans-flavan-3-ol ratios, obtained by integration of the respective H/C-4 cross-peak

9 contours, were also related to determinations made by thiolysis $\left(\mathrm{R}^{2}=0.89\right)$. Overall, ${ }^{1} \mathrm{H}-{ }^{13} \mathrm{C}$

10 HSQC NMR spectroscopy appears to be a viable alternative to thiolysis for estimating PC/PD

11 and cis/trans ratios of CT, if precautions are taken to avoid integration of cross-peak contours of

12 contaminants.

13 KEYWORDS: Condensed tannins, proanthocyanidins, procyanidins, prodelphinidins, nuclear

14 magnetic resonance spectroscopy, NMR, thiolysis 
16 Condensed tannins (CTs) (also referred to as proanthocyanidins or PACs) represent a class of

17 polyphenolic plant secondary metabolites that are composed of oligomers and polymers of

18 flavan-3-ols. ${ }^{1,2}$ These structures vary not only in flavan-3-ol subunit composition, but also in

19 interflavan-3-ol bond connectivity and mean degree of polymerization (mDP). Condensed

20 tannins are most commonly composed of procyanidin (PC) subunits derived from catechin and

21 epicatechin and of prodelphinidin (PD) subunits derived from gallocatechin and

22 epigallocatechin. Substituents at C-2 and C-3 in the C-ring of epicatechin and epigallocatechin

23 have a cis configuration while catechin and gallocatechin possess a trans stereochemical

24 orientation (Figure 1). These subunits are typically interconnected by C4-C8 interflavan-3-ol

25 linkages (classified as a B-type linkage, Figure 1), but other less common interunit linkages such 26 as the C4-C6 also occur in CTs.

A major point of interest in CTs stems from the potential positive impact they could bring to the agricultural industry because of their ability to modulate proteolysis during forage

29 conservation and ruminal digestion, ${ }^{3-7}$ to prevent bloat, ${ }^{8}$ reduce intestinal parasite burdens ${ }^{9}$ and 30 lessen methane emissions from ruminants. ${ }^{10,11}$ It is thought that the CT composition may play a

31 role in how effectively they impart their biological effects on each of these outcomes, improving

32 both the economical and environmental sustainability of ruminant farm operations. Thus, results

33 from in vitro and in vivo experiments where CT content is known and the composition is well-

34 defined should reveal CT types and levels that are required for optimizing ruminant health and

35 productivity. Such information would help plant breeders with selection for CT content and

36 structure and also help identify plant varieties that are good candidates for genetic modification. 
Analytical techniques allowing for the rapid assessment of chemical structures of CT mixtures within and isolated from plant materials remain a high priority. ${ }^{12}$ Development of robust analytical methods is required to gain a better understanding of how CTs affect the

40 interdependency of CT/protein structure-activity relationships. Owing to the structural complexity of CTs, novel approaches are needed for their analysis, including new techniques to

42 corroborate data from existing methods. These analytical techniques are needed for analyzing CT

43 mixtures as these are relevant, and applicable to, nutritional and health research on CTs for both 44 humans $^{13}$ and animals. ${ }^{14}$

A variety of analytical techniques have been developed for the characterization and analysis of condensed tannins. Thiolysis with benzyl mercaptan ${ }^{15,16}$ is one of the most common

47 methods to obtain compositional and structural data on in situ or isolated CT. ${ }^{17}$ This method involves acid-catalyzed degradation of CT polymers into reactive monomeric cationic subunits

49 which are subsequently trapped with nucleophiles, such as benzyl mercaptan, providing stable monomeric flavan-3-ol adducts. In this method, extension units are converted into stable C-4

51 thio ethers whereas terminal units of the polymers are liberated as intact flavan-3-ol monomers.

52 HPLC analysis of the mixtures obtained from these depolymerization studies allows qualitative 53 and quantitative assessment of CTs composition in terms of ratios of PC/PD and cis/trans

54 subunits and overall mDP. It can thus be used to calculate the purity of isolated CT samples

55 based on the total flavan-3-ol yield. Currently, thiolysis represents one of the most useful 56 techniques available for the analysis of CT composition.

57 One dimensional (1D) NMR spectroscopic studies have been used previously to 58 determine the compositional aspects of isolated condensed tannin samples by either solution state $59{ }^{13} \mathrm{C}$ NMR spectroscopy ${ }^{18-27}$ or cross-polarization magic angle spinning (CPMAS) solid state ${ }^{13} \mathrm{C}$ 
60

61

62

63

64

65

66

67

68

NMR spectroscopy. ${ }^{28-31}$ Solution state ${ }^{13} \mathrm{C}$ NMR spectroscopy has been utilized for determination of PC/PD ${ }^{18-20,22-27}$ and cis/trans ratios, ${ }^{18,19,22,24-27}$ estimations of $\mathrm{mDP}^{18-20,22,}$ 24,26,27 and the identification of C4-C6 and C4-C8 linkages. ${ }^{20,21}$ These NMR techniques, however, suffer from broad and often times unresolved signals, long acquisition times, and low signal-tonoise ratios which hamper an accurate assessment of CT composition. Solid phase studies of CTcontaining plant material have been conducted using ${ }^{13} \mathrm{C}$ CPMAS NMR techniques. ${ }^{28-31}$ Although this technique provides good signal-to-noise ratios, signals in the spectra are still broad and frequently overlap with non-CT signals. In addition, ${ }^{13} \mathrm{C}$ CPMAS requires the use of highly specialized equipment.

By contrast, common two-dimensional (2D) NMR techniques have not been extensively explored for assessing the composition of either purified CTs or CT present in whole plant materials. ${ }^{32}$ Here we report the use of ${ }^{1} \mathrm{H}-{ }^{13} \mathrm{C}$ HSQC NMR spectroscopy as a means to determine PC/PD and cis/trans ratios of isolated CT samples.

\section{MATERIALS AND METHODS}

\section{General Procedure for Purification and Characterization of Condensed Tannins.}

Condensed tannins were purified from dried and milled plant material and analyzed for CT composition and purity as previously described. ${ }^{15,16}$ Briefly, dried plant material was milled (typically using a cyclone mill) containing a 1 or $0.5 \mathrm{~mm}$ screen and the resulting ground material was extracted with 7:3 acetone/water $(3 \times 10 \mathrm{~mL} / \mathrm{g}$ of dried material) and filtered. The combined filtrates were concentrated on a rotary evaporator $\left(<40^{\circ} \mathrm{C}\right)$ to remove acetone and the resulting aqueous layer was extracted with one-half volume of dichloromethane $(2 \mathrm{x})$ and was freeze-dried. The freeze-dried residue was purified in one of two ways. The first method 
82 involved dissolving the freeze-dried residue in water and applying the resulting mixture to the

83 top of a Sephadex LH-20 column pre-packed in water. The column was eluted with water,

84 removing a majority of the carbohydrates present. Column elution was continued with 3:7

85 acetone/water (providing sample fraction 1) followed by elution of the column with 1:1

86 acetone/water to give sample fraction 2, which typically contained CTs of highest purity.

87 Alternatively, the dried extraction residue is adsorbed onto Sephadex LH-20 as a 1:1 methanol/water solution to provide a mixture with the consistency of wet sand. This material is then placed in a Buchner funnel and consecutively rinsed with methanol/water (1:1) followed by a series of acetone/water mixtures $(1: 1,7: 3,9: 1)$ with each rinsing conducted three times with a 5 mL solvent per gram of Sephadex LH-20. The three rinse filtrates for each solvent were pooled, 92 concentrated on a rotary evaporator $\left(<40^{\circ} \mathrm{C}\right)$ to remove the volatile solvent and freeze-dried. In 93 both purification methods, the freeze-dried samples were analyzed by ${ }^{1} \mathrm{H}_{-}{ }^{13} \mathrm{C}$ HSQC NMR 94 spectroscopy to assess relative purity and/or thiolysis to provide a numerical purity.

95 NMR Spectroscopy. ${ }^{1} \mathrm{H},{ }^{13} \mathrm{C}$ and ${ }^{1} \mathrm{H}-{ }^{13} \mathrm{C}$ HSQC NMR spectra were recorded at $27{ }^{\circ} \mathrm{C}$ on a

972.1 software and a cryogenically cooled $5-\mathrm{mm}$ TXI ${ }^{1} \mathrm{H} /{ }^{13} \mathrm{C} /{ }^{15} \mathrm{~N}$ gradient probe in inverse geometry. Spectra were recorded in DMSO- $d_{6} /$ pyridine- $d_{5}(4: 1)$ mixtures and were referenced to 99 the residual signals of DMSO- $d_{6}\left(2.49 \mathrm{ppm}\right.$ for ${ }^{1} \mathrm{H}$ and $39.5 \mathrm{ppm}$ for ${ }^{13} \mathrm{C}$ spectra $) .{ }^{13} \mathrm{C}$ NMR 100 spectra were obtained using $5 \mathrm{~K}$ scans (acquisition time 4 h 30 min each). For ${ }^{1} \mathrm{H}-{ }^{13} \mathrm{C}$ HSQC

101 experiments, spectra were obtained using 128 scans (acquisition time 18 h 30 min each) obtained 102 using the standard Bruker pulse program (hsqcegtpsi) with the following parameters: Acquisition: TD 1024 (F2), 320 (F1); SW 10.0 ppm (F2), 160 ppm (F1); O1 2500.65 Hz; O2 104 11,318.20 Hz; D1 = 1.50 s; CNST2 = 145. Acquisition time: F2 channel, 102.55 ms, F1 channel 
105

106

107

108

109

110

111

112

113

114

115

116

117

118

119

120

121

122

123

124

125

126

7.9511 ms. Processing: SI =1024 (F2, F1), WDW = QSINE, LB = $1.00 \mathrm{~Hz}(\mathrm{~F} 2), 0.30 \mathrm{~Hz}(\mathrm{~F} 1)$;

PH_mod = pk; Baseline correction ABSG =5 (F2, F1), BCFW = 1.00 ppm, BC_mod = quad

$(\mathrm{F} 2)$, no $(\mathrm{F} 1)$; Linear prediction $=$ no $(\mathrm{F} 2)$, LPfr $(\mathrm{F} 1)$. Samples sizes used for these spectra ranged

from 10-15 mg providing NMR sample solutions with concentrations of 20-30 mg/mL.

Calculating Procyanidin/Prodelphinidin (PC/PD) and Cis/trans-Flavan-3-ol Ratios. The

percentage of PCs in the CT sample was calculated using the equation (1):

$$
\% \mathrm{PC}=\mathrm{PC}-6^{\prime} /\left[\mathrm{PD}-2^{\prime} 6^{\prime} / 2+\mathrm{PC}-6^{\prime}\right] \times 100
$$

Equation (1)

where PC-6' is the integration of the contour for the H/C-6' cross-peak of the PC units and PD$2^{\prime} 6^{\prime}$ is the integration of the contour for the H/C-2',6' cross-peak of the PD units. The PD-2 '-6'

value is divided by 2 to account for the signal arising from two sets of correlated nuclei. The percentage of cis isomers present in the CT sample was calculated through integration of the respective H/C-4 cis- and trans-flavan-3-ol cross-peak contours centered around ${ }^{1} \mathrm{H} /{ }^{13} \mathrm{C}$ chemical shifts of 4.5-4.8/36.0 and 4.4-4.65/37.5 ppm, respectively, and used in equation (2):

\% cis-flavan-3-ols = cis-flavan-3-ols/cis-flavan-3-ols + trans-flavan-3-ols] x 100 Equation (2)

Integrations of cross-peaks were performed in triplicate and the values were averaged.

Integration of the peaks was performed using Topspin 2.1 software.

\section{RESULTS AND DISCUSSION}

We have recently shown that ${ }^{1} \mathrm{H}_{-}{ }^{13} \mathrm{C}$ HSQC NMR spectroscopy can be a useful tool when assessing the presence of $\mathrm{CT}$ in forages and detection of CT left in residues after HCl-butanol treatment, ${ }^{16}$ demonstrating the power of $2 \mathrm{D}$ NMR techniques. The current study included examining the ${ }^{1} \mathrm{H}-{ }^{13} \mathrm{C}$ HSQC NMR spectra of 22 purified CT samples prepared from nine different plant species. Based on thiolysis, the CT samples had PC/PD ratios ranging from 0/100 
127

128

129

130

131

132

133

134

135

136

137

138

139

140

to $99 / 1$, cis/trans ratios ranging from $58 / 42$ to $95 / 5$, and a CT content of 44 to $\sim 100 \%$ as determined by thiolysis (Table 1). As an example, ${ }^{1} \mathrm{H}_{-}{ }^{13} \mathrm{C}$ HSQC NMR spectrum of CT purified from Lotus pedunculatus (big trefoil, sample number 6, Table 1) is given in Figure 2A along with cross-peak assignments. The absence of significant cross-peak NMR signals from non-CT organic compounds in this spectrum also confirms a high degree of purity of this sample.

Determination of PC/PD Ratios. Quantification of signals arising from polymeric materials by ${ }^{1} \mathrm{H}-{ }^{13} \mathrm{C}$ HSQC NMR spectroscopy is often hampered by nuclei having differing $T 1$ and $T 2$ relaxation times and differences in coupling constants and resonance offset effects. ${ }^{33}$ The presence of these effects results in skewing of cross-peak signal contour volumes and thus typically limits the utility of these contours for quantifying structural information. Usually these effects require special spectroscopic treatments, alterations in NMR acquisition parameters such as changes in pulse sequences or increased relaxation delays, before reliable quantification can be $_{\text {made. }}^{34-36}$

In the ${ }^{1} \mathrm{H}-{ }^{13} \mathrm{C}$ HSQC NMR spectra of these samples, a combination of the nuclei $T 1$ and $T 2$ relaxation and resonance offset effects can be observed for most cross-peak signals. The results of these effects lead to cross-peak contours in the spectra whose volumes are not proportional to the corresponding nuclei ratios. As a prime example, integration of the contours for signals arising from $\mathrm{H} / \mathrm{C}-2^{\prime}, 5^{\prime}$ of $\mathrm{PC}$ units versus those from $\mathrm{H} / \mathrm{C}-6^{\prime}$ of $\mathrm{PC}$ units would normally provide a ratio of 2:1 if none of the above mentioned effects were observed (Figure 2B). However, the integration ratios of $\mathrm{H} / \mathrm{C}-2^{\prime}$ ', $5^{\prime}$ versus $\mathrm{H} / \mathrm{C}-6^{\prime}$ cross-peak contours in PC containing samples from this study showed wide variability with a range from 2.37:1 to 3.86:1 $(\mathrm{n}=17$, ave. $=3.15, \mathrm{SD} \pm 0.48)$. Most of the signals in the ${ }^{1} \mathrm{H}-{ }^{13} \mathrm{C}$ HSQC NMR spectra of these purified CT samples followed this trend. A comparison of integration values obtained from the 
cross-peak contours could not be directly correlated with theoretical relative intensities of the nuclei giving rise to the signal. Similarly, in an attempt to assess the mean degrees of polymerization $(\mathrm{mDP})$ of these samples, integration of the terminal methylene unit versus any of the other CT cross-peak signals in the spectra also led to no obvious correlation with the thiolysis data of this study. It is worth noting that even integrations of the C-4 methylene units of the flavan-3-ol monomers catechin, epicatechin and epigallocatechin under identical conditions only integrate, on average, to $72 \%$ of other signals present in the ${ }^{1} \mathrm{H}-{ }^{13} \mathrm{C}$ HSQC NMR spectrum. However, integration ratios of H/C-6' cross-peak signals from PC units and the H/C-2', 6' cross-peak signal from PD units did show an extremely strong and unbiased relationship with PC/PD estimates from thiolysis determinations (Figure 3A). Thus, this is the first time that ${ }^{1} \mathrm{H}-$ ${ }^{13} \mathrm{C}$ HSQC NMR data from purified CT samples have been corroborated with data from an alternative method (thiolysis) to quantify compositional characteristics of CTs. Separate NMR analyses conducted on a limited set of other purified CT samples at the University of Reading confirmed this method as providing reliable PC/PD ratios.

It is not clear how all of the parameters controlling contour intensities are interrelated: do the nuclei involved impart the same or similar $T 1$ and $T 2$ relaxation times, coupling constants and resonance offset effects, allowing for accurate comparison of the two contours, or is this simply a coincidence of cancellation of the effects? Answers to these questions remain to be determined.

To test for variability in sample to sample preparation and data acquisition, we prepared duplicate NMR solutions from the same CT samples and obtained NMR spectra of these preparations on different days. These results are given in Table 2. As shown, there is excellent 
172 reproducibility of the method between these duplicate runs. In all, these experiments prove that

173 this is a robust method for estimation of PC/PD ratios in purified CT samples.

174 Determination of Cis/Trans Flavan-3-ol Ratios. In order to assess cis- and trans-flavan-3-ol

175 ratios (i.e. ratio of epicatechin and epigallocatechin versus catechin and gallocatechin) in these

176 samples we focused on the H/C-4 cross-peak signal (Figure 2C). It has been reported ${ }^{32}$ that this

177 signal is segregated into two cross-peaks with ${ }^{1} \mathrm{H} /{ }^{13} \mathrm{C}$ chemical shifts of $\sim 4.5-4.8 / 36.0$ and $\sim 4.4-$

$1784.65 / 37.5$ ppm for the cis- and trans-flavan-3-ol subunits, respectively. The integration of cross-

179 peak signals in ${ }^{1} \mathrm{H}_{-}{ }^{13} \mathrm{C}$ HSQC NMR spectra of the same nuclei with the same connectivity in near 180 identical electronic environments should be straight-forward as they should possess similar, if 181 not identical, $T 1$ and $T 2$ relaxation times and pose little or no differences in coupling constants 182 and resonance offset effects. Thus, we should be able to use the data obtained from these ${ }^{1} \mathrm{H}-{ }^{13} \mathrm{C}$ 183 HSQC NMR spectra to directly measure this structural element of isolated CTs. The percentage 184 of cis isomers present in the CT sample was calculated through integration of the respective H/C1854 cis and trans cross-peak contours (Figure 2C). Integration ratios from these contours provided 186 strongly related but biased estimates of cis/trans ratios relative to thiolysis (Figure 3B). A

187 literature search revealed that this segregation of the cis and trans signals of flavan-3-ol moieties 188 is most likely not absolute and this could provide an explanation for the bias in cis/trans 189 estimates relative to thiolysis. NMR spectroscopic data from epicatechin (cis) oligomers report $190{ }^{13} \mathrm{C}$ chemical shift in the range of $37.5 \mathrm{ppm}$, overlapping into the previously designated "trans" 191 signal region. ${ }^{37,38}$ The lack of signal segregation is more pronounced in structures containing C4192 C6 interflavanyl linkages. ${ }^{38,39}$ Thus, overlapping of signals from $c i s$ - and trans-flavan-3-ol 193 subunits is the most likely contributing factor for slightly larger discrepancies between the 
194 thiolysis/NMR correlations for cis/trans-flavan-3-ol subunit assessments, and may also be 195 responsible for the biased regression fit (Figure 3B).

196 Precautions. The first issue here, as with most analytical techniques, is to obtain a spectrum with 197 strong signal to noise ratio before attempting to integrate the data. If sample size is limited, 198 extended acquisition times need to be considered. When using this technique on samples of low 199 purity it is imperative that the user be able to recognize any non-CT impurity signals present and 200 avoid incorporating them into the integration values. For PC/PD ratio evaluations, we have found 201 that the signals indicated in Figure 2B are the most common impurity signals which may 202 interfere in obtaining reliable results. These signals most likely arise from trace amounts of non203 CT polyphenols present in the sample. For the assessment of cis/trans ratios, the problem of 204 integration of non-CT impurities does not seem to be an issue. The H/C-4 cross-peak signals 205 appear, even in spectra of whole plant material, in an area void of other non-CT signals. The 206 major issue in the cis/trans ratio assessment is the resolution of the two signals. In some cases 207 these signals are not well resolved (Figure 3B) and care needs to be taken in selecting the 208 integration areas.

209 In conclusion, the method developed now permits analytical assessment, via $2 \mathrm{D}^{1} \mathrm{H}_{-}{ }^{13} \mathrm{C}$ 210 HSQC NMR spectroscopy, of two specific chemical properties of purified CT samples: PC/PD 211 and cis/trans ratios. Purified CT samples examined encompass the entire range of 212 procyanidin/prodelphinidin ratios from 0/100 to 99/1 and a substantial range of cis/trans-flavan213 3-ol ratios from 58:42 to 95.5:4.5. The observations outlined here also provide validation of 214 thiolysis data for analysis of CT composition. In contrast to thiolysis, NMR spectroscopy 215 represents a non-destructive analytical tool, which can be important when sample quantities are 216 limited. Thiolysis requires ca $4 \mathrm{mg}$ for a single determination, whereas NMR analysis requires 
217 only $10 \mathrm{mg}$ for an $18 \mathrm{~h}$ acquisition time using the described instrumentation. No additional

218 straight-forward correlations were found upon examination of other cross-peak signals in these

$219{ }^{1} \mathrm{H}_{-}{ }^{13} \mathrm{C}$ HSQC NMR spectra. Additional spectroscopic examination of these samples is

220 warranted to investigate whether other significant structural information can be obtained using

221 quantitative ${ }^{1} \mathrm{H}^{13} \mathrm{C}$ HSQC NMR data ${ }^{34-36}$ or alternative NMR techniques.

\section{AUTHOR INFORMATION}

225 Corresponding Author

226 *(W. E. Zeller) E-mail: wayne.zeller@ ars.usda.gov, Phone: 608-890-0071, Fax: 608-890-0076,

\section{ACKNOWLEDGEMENTS}

229 This work was funded in part by a USDA-ARS specific cooperative agreement \#58-3655-0-155F

230 with the University of Reading, UK and was supported by a European Union Marie Curie Initial

231 Training Network (PITN-GA-2011-289377 ('LegumePlus'). The authors would like to

232 acknowledge the technical of assistance of Abert Vang, Jane Marita for assistance with NMR

233 experiments, Scott Kronberg for lespedeza pellets and Heike Hofstetter for valuable discussions.

234 Mention of trade names or commercial products in this article is solely for the purpose of

235 providing specific information and does not imply recommendation or endorsement by the U.S.

236 Department of Agriculture. 
$241{ }^{1} \mathrm{H}_{-}{ }^{13} \mathrm{C}$ HSQC, proton-carbon-13 heteronuclear single quantum coherence ; NMR, nuclear

242 magnetic resonance; PC, procyanidin; PD, prodelphinidin; cis, 2,3-cis; trans, 2,3-trans; CT,

243 condensed tannins; $\mathrm{mDP}$, mean degree of polymerization; ${ }^{13} \mathrm{C}$, carbon-13; CPMAS, cross

244 polarization magic angle spinning; 1D, one dimensional; 2D, two dimensional; 5K, five

245 thousand; DMSO- $d_{6}$, perdeuterated dimethyl sulfoxide.

246

(1) Hagerman, A. E. Tannin Handbook, Miami University, Oxford, Ohio (2002). Available:

250 (2) Schofield, P.; Mbugua, D. M.; Pell, A. N. Analysis of condensed tannins: a review. Anim.

251 Feed Sci. Technol. 2001, 91, 21-40.

252 (3) Min, B. R.; Barry, T. N.; Attwood, G. T.; McNabb. W. C. The effect of condensed tannins 253 on the nutrition and health of ruminants fed fresh temperate forages: a review. Anim. Feed Sci.

254 Tech. 2003, 106, 3-19.

255 (4) Waghorn, G. C.; Douglas, G. B.; Niezen, J. H.; McNabb, W. C.; Foote, A. G. Forages with 256 condensed tannins - their management and nutritive value for ruminants. Proc. N. Z. Grassl.

257 Assoc. 1998, 60, 89-98.

258 (5) Barry, T. N.; McNabb, W. C. The implications of condensed tannins on the nutritive value of 259 temperate forages fed to ruminants. Br. J. Nutr. 1999, 81, 263-272.

260 (6) Albrecht, K. A.; Muck, R. E. Proteolysis in ensiled forage legumes that vary in tannin 261 concentration. Crop Sci. 1991, 31, 464-469.

262 (7) Coblentz, W. K.; Grabber, J. H. In situ protein degradation of alfalfa and birdsfoot trefoil 
263 hays and silages as influenced by condensed tannin concentration. J. Dairy Sci. 2013, 96, 31202643137.

265 (8) McMahon, L. R., T.A. McAllister, B.P. Berg, W. Majak, S.N. Acharya, J.D. Popp, B.E.

266 Coulman, Y. Wang, and Cheng, K.-J. A review of the effects of forage condensed tannins on 267 ruminal fermentation and bloat in grazing cattle. Can. J. Plant. Sci. 2000, 80, 469-485.

268 (9) Hoste, H.; Jackson, F.; Athanasiadou, S.; Thamsborg, S. M.; Hoskin, S. O. The effects of 269 tannin-rich plants on parasitic nematodes in ruminants. Trends Parasitol. 2006, 22, 253-261.

270 (10) Patra, A. K.; Saxena, J. A new perspective on the use of plant secondary metabolites to 271 inhibit methanogenesis in the rumen. Phytochemistry 2010, 71, 1198-1222.

272 (11) Pellikaan, W. F.; Stringano, E.; Leenaars, J.; Bongers, D. J. G. M.; van Laar-van Schuppen, 273 S.; Plant, J.; Mueller-Harvey, I. Evaluating effects of tannins on extent and rate of in vitro gas 274 and $\mathrm{CH}_{4}$ production using an automated pressure evaluation system (APES). Anim. Feed Sci. 275 Technol. 2011, 166-167, 377-390.

276 (12) Hümmer, W.; Schreier, P. Analysis of proanthocyanidins. Mol. Nutr. Food Res. 2008, 52, $277 \quad 1381-1398$.

278 (13) Santos-Buelga, C.; Scalbert, A. Proanthocyanidins and tannin-like compounds- nature, 279 occurrence, dietary intake and effects on nutrition and health. J. Sci. Food Agric. 2000, 80, $280 \quad 1094-1117$.

281 (14) Patra, A. K.; Saxena, J. Exploitation of dietary tannins to improve rumen metabolism and 282 ruminant nutrition. J. Sci. Food Agric. 2011, 91, 24-37.

283 (15) Gea, A.; Stringano, E.; Brown, R. H.; Mueller-Harvey, I. In situ analysis and structural 284 elucidation of sainfoin (Onobrychis viciifolia) tannins for high-throughput germplasm screening. 285 J. Agric. Food Chem. 2011, 59, 495-503. 
(16) Grabber, J. H.; Zeller, W. E.; Mueller-Harvey, I. Acetone enhances the direct analysis of procyanidin- and prodelphinidin-based condensed tannins in Lotus species by the butanol-HCl-iron assay. J. Agric. Food Chem. 2013, 61, 2669-2678.

(17) Stringano, E.; Hayot Carbonero, C.; Smith, L. M. J.; Brown, R. H.; Mueller-Harvey, I. Proanthocyanidin diversity in the EU 'HealthyHay' sainfoin (Onobrychis viciifolia) germplasm collection. Phytochemistry 2012, 77, 197-208.

(18) Czochanska, Z.; Foo, L. Y.; Newman, R. H.; Porter, L. J.; Thomas, W. A. Direct proof of a homogeneous polyflavan-3-ol structure for polymeric proanthocyanidins. J. Chem. Soc., Chem. Comm. 1979, 375-377.

(19) Czochanska, Z.; Foo, L. Y.; Newman, R. H.; Porter, L. J. Polymeric proanthocyanidins. Stereochemistry, structural units, and molecular weight. J. Chem. Soc., Perk. Trans. I. 1980, 2278-2286.

(20) Pizzi A.; Stephanou, A. A comparative $\mathrm{C}^{13}$ NMR study of polyflavonoid tannin extracts for phenolic polycondensates. J. Appl. Polym. Sci. 1993, 50, 2105-2113.

(21) Newman, R. H.; Porter, L. J.; Foo, L. Y.; Johns, S. R.; Willing, R. I. High-resolution ${ }^{13}$ C NMR studies of proanthocyanidin polymers (condensed tannins). Magn. Reson. Chem. 1987, 25, $118-124$

(22) Foo, L. Y.; Lu, Y.; Molan, A. L.; Woodfield, D. R.; McNabb, W. C The phenols and prodelphinidins of white clover flowers. Phytochemistry 2000, 54, 539-548.

(23) Ossipova, S.; Ossipov, V.; Haukioja, E.; Loponen, J.; Pihlaja, K. Proanthocyanidins of mountain birch leaves: Quantification and properties. Phytochem. Anal. 2001, 12, 128-133. 
(24) Kraus, T. E. C.; Yu, Z.; Preston, C. M.; Dahlgren, R. A.; Zasoski, R. J. Linking chemical reactivity and protein precipitation to structural characteristics of foliar tannins. J. Chem. Ecol., 2003, 29, 703-730.

(25) Qa'dan, F.; Nahrstedt, A.; Schmidt, M.; Mansoor, K. Polyphenols from Ginkgo biloba. Sci. Pharm. 2010, 78, 897-907.

(26) Zhang, L.-L.; Lin, Y.-M.; Hai-Chao Zhou, H.-C.; Wei, S.-D.; Chen, J.-H. Condensed tannins from mangrove species Kandelia candel and Rhizophora mangle and their antioxidant activity. Molecules 2010, 15, 420-431.

(27) Chai, W.-M.; Shi, Y.; Feng, H.-L.; Qiu, L.; Zhou, H.-C.; Deng, Z.-W.; Yan, C.-L.; Chen, Q.-X. NMR, HPLC-ESI-MS, and MALDI-TOF MS analysis of condensed tannins from Delonix regia (Bojer ex Hook.) Raf. and their bioactivities. J. Agric. Food Chem. 2012, 60, 5013-5022. (28) Hoong, Y. B.; Pizzi, A.; Tahir, P. Md.; Pasch, H.; Characterization of Acacia mangium polyflavonoid tannins by MALDI-TOF mass spectrometry and CP-MAS ${ }^{13} \mathrm{C}$ NMR. Eur. Polym. J. 2010, 46, 1268-1277.

(29) Reid, D. G.; Bonnet, S. L.; Kemp, G.; Van der Westhuizen, J. H. Analysis of commercial proanthocyanidins. Part 4: Solid state ${ }^{13} \mathrm{C}$ NMR as a tool for in situ analysis of proanthocyanidin tannins, in heartwood and bark of quebracho and acacia, and related species. Phytochemistry 2013, 94, 243-248.

(30) Romer, F. H.; Underwood, A. P.; Senekal, N. D.; Bonnet, S. L.; Duer, M. J.; Reid, D. G.; Van der Westhuizen, J. H. Tannin fingerprinting in vegetable tanned leather by solid state NMR spectroscopy and comparison with leathers tanned by other processes. Molecules 2011, 16, 12401252. 
329 (31) Lorenz, K.; Preston, C. M. Characterization of high-tannin fractions from humus by 330 carbon-13 cross-polarization and magic-angle spinning nuclear magnetic resonance. J. Environ. 331 Qual. 2002, 31, 431-436.

332 (32) Zhang, L.; Gellerstedt, G. 2D Heteronuclear $\left({ }^{1} \mathrm{H}-{ }^{13} \mathrm{C}\right)$ single quantum correlation (HSQC) 333 NMR analysis of norway spruce bark components. In Characterization of Lignocellulosic 334 Materials, First Edition, Hu, T. Q., Ed.; Blackwell Publishing: Oxford, United Kingdom, 2008, $3351,3-16$.

(33) Zhang, L.; Gellerstedt, G. Quantitative 2D HSQC NMR determination of polymer structures 337 by selecting suitable internal standard references. Magn, Res. Chem. 2007, 45, 37-45.

338 (34) Sette, M.; Lange, H.; Crestini, C. Quantitative HSQC analyses of lignin: A practical 339 comparison. Comput. Struct. Biotechnol. J. 2013, 6, e201303016.

340 (35) Hu, K.; Westler, W. M.; Markley, J. L. Simultaneous quantification and identification of 341 individuals chemicals in metabolite mixtures by two-dimensional extrapolated time-zero ${ }^{1} \mathrm{H}-{ }^{13} \mathrm{C}$ 342 HSQC (HSQC $)$ ). J. Am. Chem. Soc. 2011, 133, 1662-1665.

343 (36) Heikkinen, S.; Toikka, M. M.; Karhunen, P. T.; Kilpeläinen, I. A. Quantitative 2D HSQC 344 (Q-HSQC) via suppression of $J$-dependence of polarization transfer in NMR spectroscopy: 345 Application to wood lignin. J. Am. Chem. Soc. 2003, 125, 4362-4367.

346 (37) Shoji, T.; Mutsuga, M.; Nakamura, T.; Kanda. T.; Akiyama, H.; Goda, Y. Isolation and 347 structural elucidation of some procyanidins from apple by low-temperature nuclear magnetic 348 resonance. J. Agric. Food Chem. 2003, 51, 3806-3813.

349 (38) Nakashima, S.; Oda, C.; Masuda, S.; Tagashira, M.; Kanda, T. Isolation and structure 350 elucidation of tetrameric procyanidins from unripe apples (Malus pumila cv. Fuji) by NMR 351 spectroscopy. Phytochemistry 2012, 83, 144-152. 
352 (39) Cui, C.-B.; Tezuka, Y.; Yamashita, H.; Kikuchi, T.; Nakano, H.; Tamaoki, T.; Park, J.-H. 353 Constituents of a fern, Davallia mariesii Moore. V. Isolation and structures of davallin, a new 354 tetrameric proanthocyanidin, and two new phenolic glycosides. Chem. Pharm. Bull. 1993, 41, 355 1491-1497. 
Figure 1. Structures of common flavan-3-ol monomeric subunits found in condensed tannins (left). A condensed tannin tetramer (right) showing C4-C8 (B-Type) linkages, PC and PD extender units and a terminal unit.

Figure 2. (Panel A) Signal assignments for the ${ }^{1} \mathrm{H}-{ }^{13} \mathrm{C}$ HSQC NMR spectrum $(500 / 125 \mathrm{MHz}$, DMSO- $d_{6} /$ pyridine- $\left.d_{5}, 4: 1\right)$ of purified condensed tannin sample (Table 1, Sample Number 6) from Lotus pedunculatus (big trefoil) leaves; (Panel B) B-Ring aromatic region cross-peak signals including H/C-2',6' PD signal and the H/C-2' ,5' and 6' signals from procyanidin units; and (Panel C) H/C-4 cis- and trans-flavan-3-ol cross-peak signals. Contours were integrated as indicated by boxes. Non-tannin related signals arising from impurities are noted and are not included in the integration.

Figure 3. (Left Panel) Proportion of procyanidin subunits in 22 isolated condensed tannin samples as determined by thiolysis vs. ${ }^{1} \mathrm{H}-{ }^{13} \mathrm{C}$ HSQC NMR. (Right Panel) Proportion of cis subunits in 22 isolated condensed tannin samples as determined by thiolysis vs. ${ }^{1} \mathrm{H}-{ }^{13} \mathrm{C}$ HSQC NMR. 
Table 1. Comparison of Data from Thiolysis and ${ }^{1} \mathrm{H}-{ }^{13} \mathrm{C}$ HSQC NMR Determinations for 22 Condensed Tannin (CT) Samples.

\begin{tabular}{|c|c|c|c|c|c|c|c|c|c|c|c|}
\hline $\begin{array}{c}\text { CT } \\
\text { Sample } \\
\text { Number }\end{array}$ & plant species & $\begin{array}{c}\text { CT content } \\
\text { (thiolysis) } \\
(\%)^{*}\end{array}$ & SD & $\begin{array}{c}\% \text { PC } \\
\text { (thiolysis) }\end{array}$ & SD & $\begin{array}{c}\% \text { PC } \\
\text { (NMR) }\end{array}$ & SD & $\begin{array}{c}\% \text { cis } \\
\text { (thiolysis) }\end{array}$ & SD & $\begin{array}{c}\% \text { cis } \\
\text { (NMR) }\end{array}$ & SD \\
\hline 1 & Lespedeza cuneata & 96.3 & 0.08 & 5.9 & 0.06 & 4.9 & 0.06 & 79.2 & 0.26 & 73.2 & 1.19 \\
\hline 2 & Lotus corniculatus & 92.5 & 0.03 & 54.0 & 0.62 & 55.6 & 1.17 & 93.3 & 0.58 & 86.8 & 0.59 \\
\hline 3 & Lotus corniculatus & 78.1 & 0.40 & 68.0 & 0.35 & 70.9 & 0.19 & 87.5 & 0.15 & 88.7 & 1.17 \\
\hline 4 & Lotus corniculatus & 75.3 & 0.01 & 57.1 & 0.12 & 60.8 & 0.32 & 91.3 & 0.13 & 87.0 & 1.58 \\
\hline 5 & Lotus pedunculatus & 108.0 & 0.01 & 16.0 & 0.07 & 14.6 & 0.80 & 81.7 & 0.22 & 69.3 & 1.63 \\
\hline 6 & Lotus pedunculatus & 91.3 & 0.35 & 25.9 & 0.29 & 23.7 & 0.28 & 78.7 & 0.23 & 75.4 & 1.22 \\
\hline 7 & Lotus pedunculatus & 85.8 & 0.01 & 17.5 & 0.06 & 17.5 & 0.50 & 79.5 & 0.05 & 71.7 & 0.45 \\
\hline 8 & Lotus pedunculatus & 80.3 & 0.41 & 28.1 & 0.17 & 29.0 & 1.02 & 74.4 & 0.15 & 71.0 & 1.79 \\
\hline 9 & Onobrychis viciifolia & 102.2 & 8.13 & 37.3 & 0.29 & 39.1 & 3.23 & 82.9 & 0.27 & 84.4 & 5.05 \\
\hline 10 & Onobrychis viciifolia & 93.7 & 4.55 & 19.2 & 0.06 & 19.1 & 0.28 & 83.3 & 0.21 & 77.9 & 1.96 \\
\hline 11 & Onobrychis viciifolia & 82.4 & 1.10 & 51.7 & 0.32 & 56.7 & 0.62 & 83.5 & 0.10 & 79.7 & 0.90 \\
\hline 12 & Onobrychis viciifolia & 44.3 & 0.17 & 57.3 & 0.07 & 59.0 & 1.45 & 68.7 & 0.00 & 64.9 & 1.10 \\
\hline 13 & Securigera varia & 56.6 & $\mathrm{n}=1$ & 18.2 & $\mathrm{n}=1$ & 22.5 & 0.17 & 89.7 & $\mathrm{n}=1$ & 87.6 & 0.56 \\
\hline 14 & Sorghum bicolor & 58.8 & 0.02 & 100.0 & 0.00 & 100.0 & 0.00 & 85.5 & 0.09 & 87.1 & 2.60 \\
\hline 15 & Theobroma cacao & 63.8 & $\mathrm{n}=1$ & 100.0 & $\mathrm{n}=1$ & 100.0 & $\mathrm{~N}$ & 93.4 & $\mathrm{n}=1$ & 100.0 & $\mathrm{~N}$ \\
\hline 16 & Theobroma cacao & 49.0 & 0.01 & 100.0 & 0.0 & 100.0 & 0.00 & 90.1 & 0.12 & 88.7 & 2.06 \\
\hline 17 & Tilia sp. & 92.7 & 0.04 & 98.5 & 0.05 & 99.2 & 0.19 & 95.5 & 0.09 & 91.2 & 0.15 \\
\hline 18 & Tilia sp. & 61.1 & 0.47 & 98.1 & 0.14 & 99.2 & 0.47 & 89.4 & 0.11 & 89.1 & 0.73 \\
\hline 19 & Trifolium repens & 120.6 & 0.01 & 0.8 & 0.00 & 0.0 & $\mathrm{~N}$ & 69.3 & 0.07 & 61.1 & 1.01 \\
\hline 20 & Trifolium repens & 111.4 & 4.80 & 1.3 & 0.00 & 0.0 & $\mathrm{~N}$ & 58.9 & 1.27 & 56.3 & 0.75 \\
\hline 21 & Trifolium repens & 106.6 & 5.08 & 0.9 & 0.04 & 0.0 & $\mathrm{~N}$ & 58.3 & 0.24 & 50.6 & 1.22 \\
\hline 22 & Trifolium repens & 97.6 & 0.01 & 1.1 & 0.04 & 0.0 & $\mathrm{~N}$ & 69.8 & 0.02 & 56.1 & 1.60 \\
\hline
\end{tabular}

$\mathrm{N}=$ Not detected; $N D=$ not determined as based on single analyses Note: \% purity refers to g tannins/100 g fraction; \% PD = 100 -

$\% \mathrm{PC} ; \%$ trans $=100-\%$ cis. 
Table 2. Comparison of Duplicate NMR Data with Thiolysis Data Obtained from

Condensed Tannin (CT) Samples (\% PC = Percentage of Procyanidins in CT Sample;

\% cis = Percentage of cis-flavan-3-ols in CT Sample).

\begin{tabular}{ccccccccc}
\hline $\begin{array}{c}\text { CT Sample } \\
\text { Number }\end{array}$ & $\begin{array}{c}\text { \% PC } \\
\text { (thiolysis) }\end{array}$ & SD & \% PC & \multicolumn{3}{c}{ \% cis } & \multicolumn{3}{c}{ \% cis } \\
\hline 3 & 68.0 & 0.35 & 70.0 & 0.49 & 87.5 & 0.15 & 88.6 & 1.32 \\
3 & & & 71.1 & 0.50 & & & 88.6 & 0.68 \\
4 & 57.1 & 0.12 & 60.4 & 0.41 & 91.3 & 0.13 & 89.8 & 0.53 \\
4 & & & 59.7 & 0.53 & & & 91.1 & 0.50 \\
6 & 26.0 & 0.29 & 24.4 & 0.35 & 78.7 & 0.23 & 75.4 & 1.02 \\
6 & & & 23.7 & 0.17 & & & 75.1 & 0.99 \\
7 & 17.5 & 0.06 & 17.5 & 0.50 & 79.5 & 0.05 & 71.6 & 0.45 \\
7 & & & 18.6 & 0.47 & & & 71.8 & 2.20 \\
11 & 51.7 & 0.32 & 56.9 & 0.42 & 83.5 & 0.10 & 79.5 & 1.20 \\
11 & & & 55.5 & 0.13 & & & 80.9 & 0.68
\end{tabular}

Note: Percentages for prodelphinidins (PD) and trans flavanols are not shown as \% PD = 100 $\% \mathrm{PC}$ and $\%$ trans $=100-\%$ cis. 


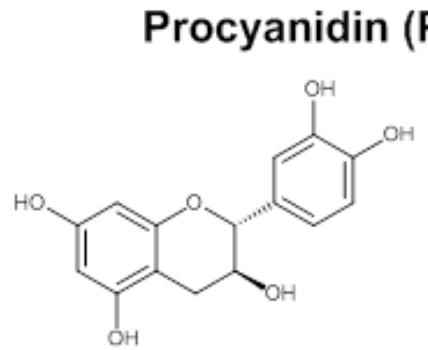

(+)-Catechin

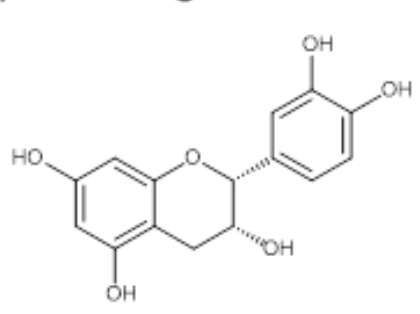

(-)-Epicatechin

Prodelphinidin (PD) Building Blocks

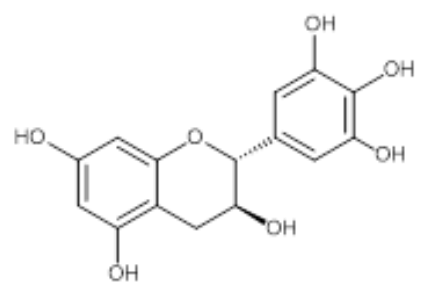

(+)-Gallocatechin<smiles>Oc1cc(O)c2c(c1)O[C@H](c1cc(O)c(O)c(O)c1)[C@H](O)C2</smiles>

(-)-Epigallocatechin

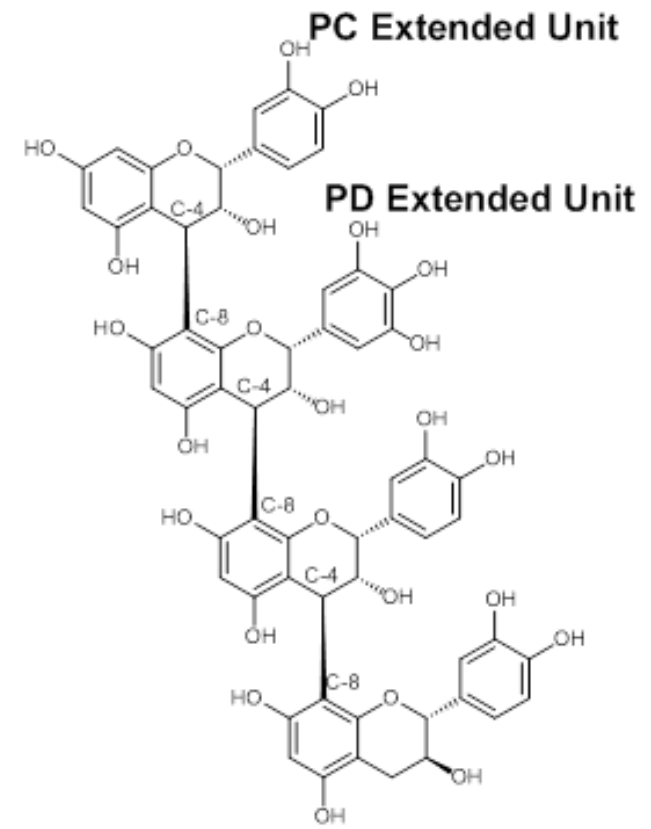

Terminal Unit

Figure 1. 


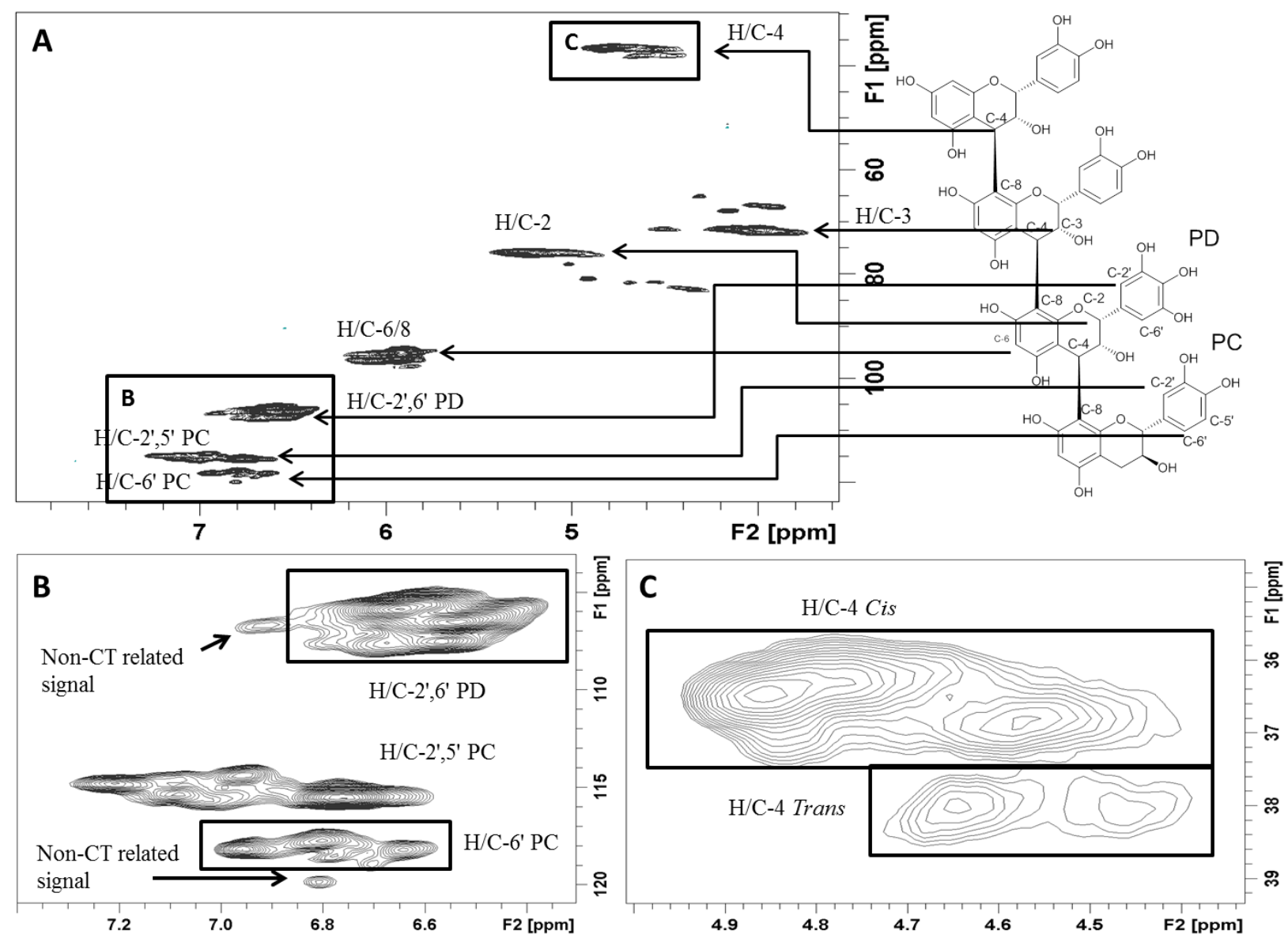

Figure 2. 


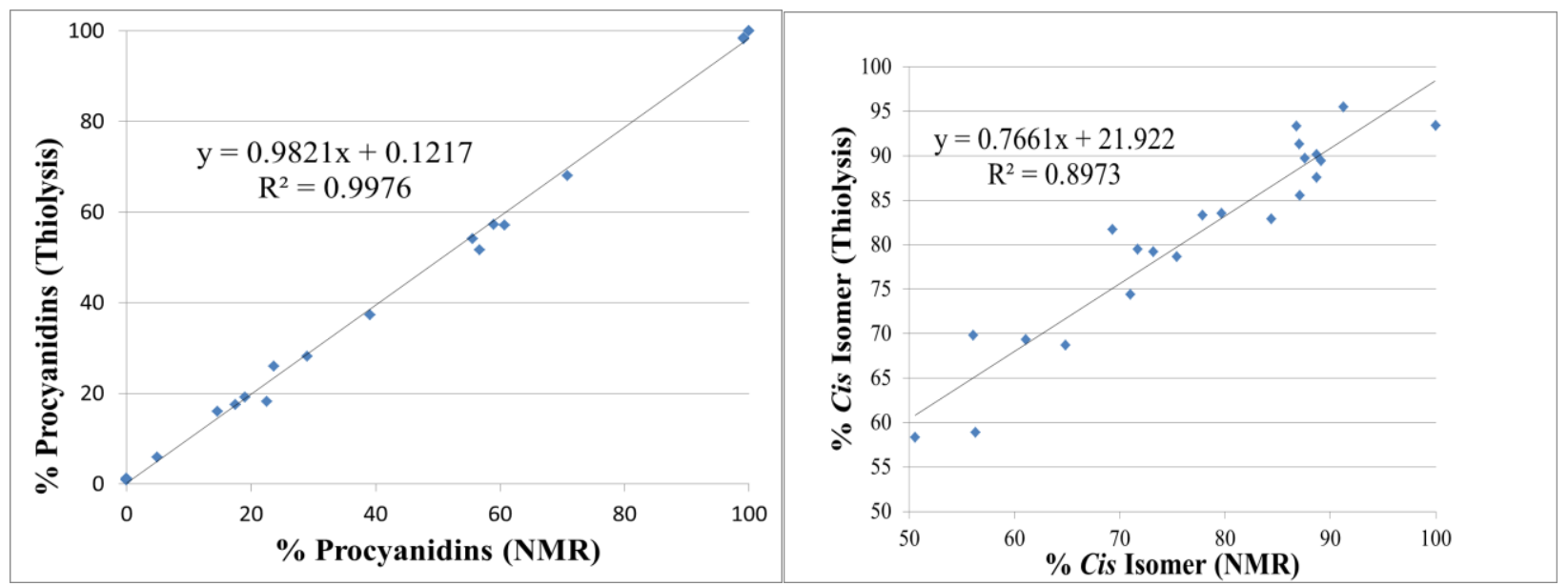

Figure 3. 
Table of Contents (TOC) Entry
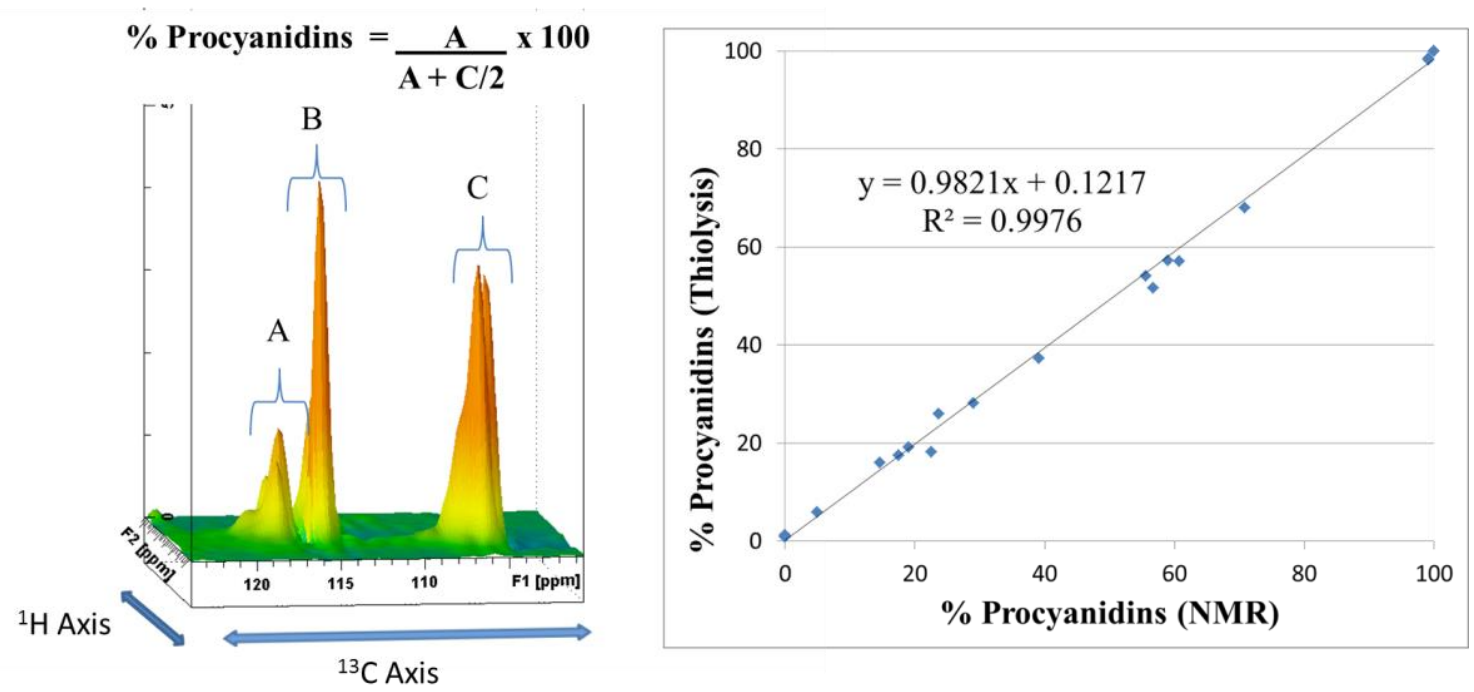